\title{
Modelagem da potencialidade hídrica das águas subterrâneas da sub- bacia do rio Siriri, Sergipe, Brasil, com base em Sistema de Informações Geográficas e técnicas de Sensoriamento Remoto
}

\author{
(http://dx.doi.org/10.4136/ambi-agua.195) \\ Daniela Dantas de Menezes Ribeiro"; Washington de Jesus Sant'Anna da Franca Rocha ${ }^{1}$, \\ Antonio Jorge Vasconcellos Garcia ${ }^{2}$ \\ ${ }^{1}$ Programa de Pós-Graduação em Modelagem em Ciências da Terra e do Ambiente, \\ Universidade Estadual de Feira de Santana (UEFS); \\ e-mail: daniela.ribeiro@ig.com.br; francarocha@gmail.com \\ ${ }^{2}$ Curso de Geologia, Universidade Federal de Sergipe; e-mail: garciageo@hotmail.com
}

\section{RESUMO}

A utilização do Sistema de Informações Geográficas (SIG) e técnicas de Sensoriamento Remoto na modelagem do potencial hídrico das águas subterrâneas geram elementos para a análise e apoio ao processo de tomada de decisão com relação à exploração desse recurso hídrico na sub-bacia. O objetivo do trabalho consiste em realizar a modelagem da potencialidade hídrica das águas subterrâneas da sub-bacia do rio Siriri-SE com base em aspectos do meio físico natural (solo, uso do solo, declividade, densidade de drenagem, densidade de lineamentos, precipitação e geologia) utilizando-se técnicas de Sensoriamento Remoto e Sistema de Informações Geográficas como ambiente de integração. No desenvolvimento do mapa de potencial hídrico das águas subterrâneas foram realizados procedimentos de processamento digital de imagens no software Envi 4.4® e de álgebra de mapas no ArcGis $9.3^{\circledR}$. O Método de Análise Hierárquica foi utilizado na modelagem para auxiliar na definição dos pesos aos diferentes critérios (mapas). A cada mapa foram atribuídas cargas para suas diferentes classes e pesos de acordo com sua influência no objetivo geral do trabalho. A integração desses mapas e a aplicação do método AHP num ambiente SIG permitiram a elaboração do mapa de potencialidade hídrica das águas subterrâneas em 5 classes de potencial: muito baixo, baixo, moderado, alto e muito alto. As vazões médias dos poços confirmam o potencial dos aquíferos Sapucari, Barreiras e Maruim uma vez que são os mais explorados na sub-bacia hidrográfica, com vazões médias de $78113 \mathrm{~L} / \mathrm{h}, 19332 \mathrm{~L} / \mathrm{h}$ e $12085 \mathrm{~L} / \mathrm{h}$ respectivamente.

Palavras-chave: água subterrânea, método de análise hierárquica, mapa, SIG.

\section{Modeling of groundwater potential of the sub-basin of Siriri river, Sergipe state, Brazil, based on Geographic Information System and Remote Sensing}

\section{ABSTRACT}

The use of Geographic Information System (GIS) and Remote Sensing for modeling groundwater potential give support for the analysis and decision-making processes about water resource management in watersheds. The objective of this work consisted in modeling the groundwater water potential of Siriri river sub-basin, Sergipe state, based on its natural environment (soil, land use, slope, drainage density, lineament density, rainfall and geology) using Remote Sensing and Geographic Information System as an integration environment. The groundwater potential map was done using digital image processing procedures of ENVI 
4.4 software and map algebra of ArcGIS 9.3 ${ }^{\circledR}$. The Analytical Hierarchy Method was used for modeling the weights definition of the different criteria (maps). Loads and weights of the different classes were assigned to each map according to their influence on the overall objective of the work. The integration of these maps in a GIS environment and the AHP technique application allowed the development of the groundwater potential map in five classes: very low, low, moderate, high, very high. The average flow rates of wells confirm the potential of aquifers Sapucari, Barriers and Maruim since they are the most exploited in this sub-basin, with average flows of 78,113 L/h, 19,332 L/h and 12,085 L/h, respectively.

Keywords: groundwater; Analytical Hierarchy Method; map; GIS.

\section{INTRODUÇÃO}

A água subterrânea consiste num recurso natural de destaque, devido a sua importância social, econômica e ambiental. No Brasil, as águas subterrâneas são intensamente explotadas e utilizadas para diversos fins, como o abastecimento humano, irrigação, indústria e lazer. No estado de Sergipe, particularmente na sub-bacia do rio Siriri, há uma grande variedade de usos para as águas dos mananciais subterrâneos, destacando-se o abastecimento doméstico, irrigação e industrial.

A utilização do Sistema de Informações Geográficas (SIG) e técnicas de Sensoriamento Remoto na modelagem do potencial hídrico das águas subterrâneas geram elementos para a análise e apoio ao processo de tomada de decisão com relação à exploração deste recurso hídrico na sub-bacia do rio Siriri. Como também, associado ao estudo hidrogeológico, auxilia no gerenciamento das águas subterrâneas.

A sub-bacia do Rio Siriri está inserida na bacia hidrográfica do Rio Japaratuba (Figura 1), possui $416 \mathrm{~km}^{2}$ e encontra-se num contexto geológico dominado por rochas da Bacia Sedimentar de Sergipe-Alagoas e de Coberturas Recentes.

O trabalho tem como objetivo realizar a modelagem do potencial hídrico das águas subterrâneas da sub-bacia do rio Siriri com base em aspectos do meio físico natural (solo, uso do solo, declividade, densidade de drenagem, densidade de lineamentos, precipitação e geologia - permeabilidade das rochas) utilizando técnicas de Sensoriamento Remoto e Sistema de Informações Geográficas como ambiente de integração.

\section{CONTEXTO HIDROGEOLÓGICO}

A sub-bacia do rio Siriri está inserida num contexto geológico dominado por rochas da Bacia Sedimentar de Sergipe/Alagoas. Observa-se também na área de estudo a presença de rochas ígneas e metamórficas do embasamento Pré-Cambriano, representadas pela unidade geológica Cornubianito Traipu. A ocorrência dessa unidade apresenta-se no mapa geológico (Brasil, 1975) da Figura 2. Recobrindo discordantemente as rochas citadas, ocorrem as Coberturas Recentes representadas pela Formação Barreiras e os sedimentos de praia e aluvião (Figura 2). 


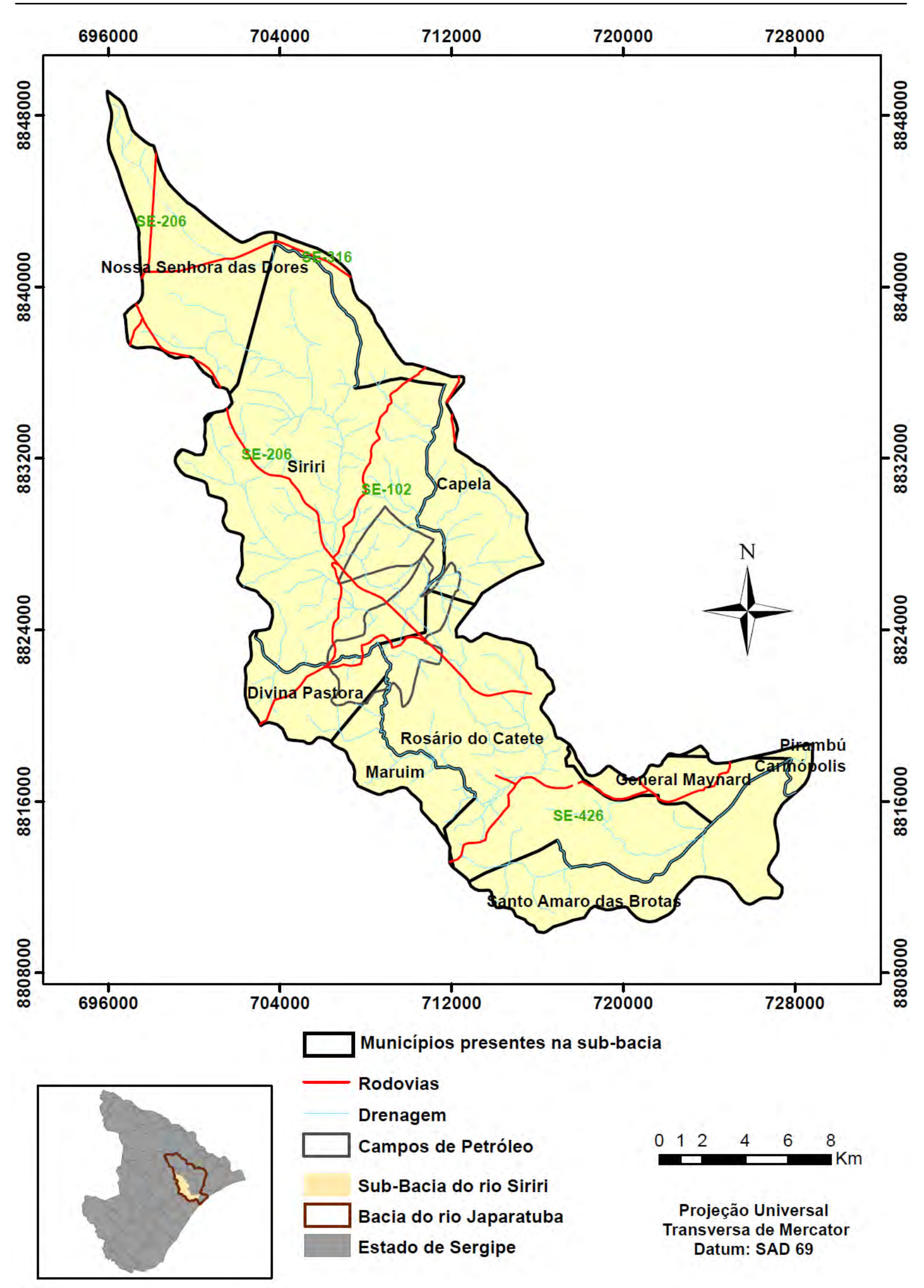

Figura 1. Mapa de localização da área de estudo. 
RIBEIRO, D. D. de M.; ROCHA, W. de J. S. da F.; GARCIA, A. J. V. Modelagem da potencialidade hídrica das águas subterrâneas da sub-bacia do rio Siriri, Sergipe, Brasil, com base em Sistema de Informações Geográficas e técnicas de Sensoriamento Remoto. Ambi-Agua, Taubaté, v. 6, n. 2, p. 206-231, 2011. (doi:10.4136/ambi-agua.195)

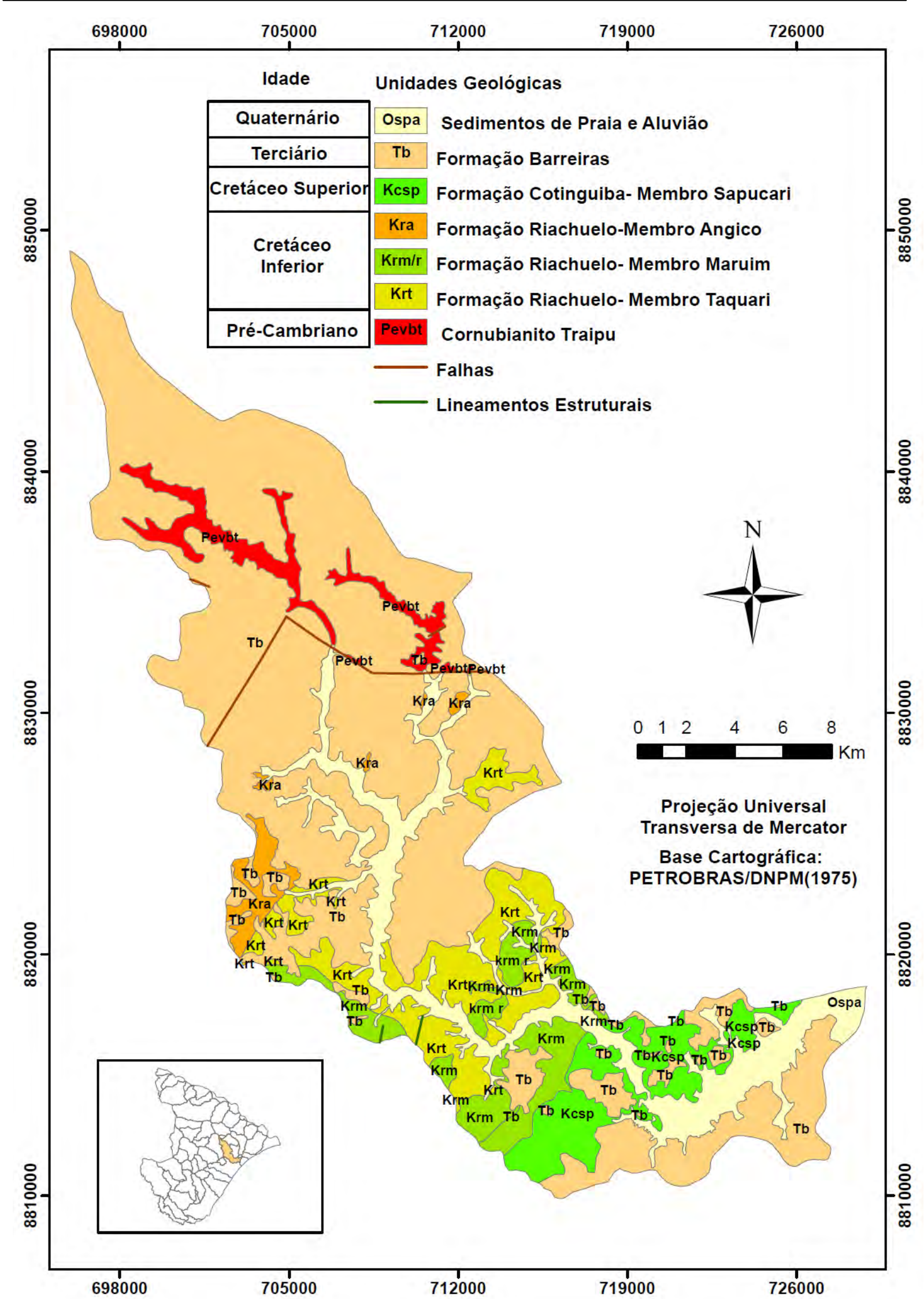

Figura 2. Mapa geológico da sub-bacia do rio Siriri (modificado de Brasil, 1975).

O Mapa Geológico da Figura 2 ilustra o "substrato” sobre o qual se instala a sub-bacia hidrográfica do rio Siriri, parte integrante da bacia hidrográfica do rio Japaratuba. Nesse mapa a bacia hidrográfica se estabelece sobre dois tipos de terrenos, os depósitos da Bacia Sergipe- 
Alagoas (dominante) e o embasamento ígneo-metamófico, ambos aflorantes pela erosão das litologias da Formação Barreiras na região. Esses terrenos encontram-se individualizados por uma falha de orientação geral NE-SW, a qual representa a borda atual falhada da Bacia Sergipe-Alagoas.

A área de estudo está inserida em dois domínios hidrogeológicos: o poroso e o fraturadocárstico. O primeiro corresponde às rochas da Bacia Sedimentar de Sergipe, a Formação Barreiras e os sedimentos de praia e aluvião. O segundo inclui as formações Riachuelo e Cotinguiba (Grupo Sergipe), que apesar de estarem inseridas na Bacia Sedimentar de Sergipe, são constituídas basicamente por rochas calcárias, que apresentam comportamento hidrogeológico distinto dos demais sedimentos, daí a sua inclusão no domínio fraturadocárstico (Brasil, 2005).

Os membros Angico e Maruim, da Formação Riachuelo, o Membro Sapucari, da Formação Cotinguiba e a Formação Barreiras apresentam boas condições de armazenamento e transmissão de água subterrânea, podendo ser considerados aquíferos. Em termos de produção, a amostragem realizada por Feitosa (1998) revela que o aquífero Sapucari, apresenta vazão média por metro perfurado de $0,66 \mathrm{~m}^{3} / \mathrm{h}(660 \mathrm{~L} / \mathrm{h})$, o Barreiras apresentou uma vazão média de $0,39 \mathrm{~m}^{3 /} \mathrm{h}(390 \mathrm{~L} / \mathrm{h})$ e o Maruim/Aguilhada uma vazão média de $0,34 \mathrm{~m}^{3} / \mathrm{h}$ $(340 \mathrm{~L} / \mathrm{h})$. Esse autor também cita que o aquífero Angico apresenta aspectos quantitativos menos favoráveis, com vazão média de $0,14 \mathrm{~m}^{3} / \mathrm{h}(140 \mathrm{~L} / \mathrm{h})$ por metro perfurado. O membro Taquari da Formação Riachuelo e o Cornubianito Traipu não apresentam informações sobre a ocorrência de água subterrânea, devido às suas características litológicas representativas de rochas com permeabilidade/porosidade praticamente nulas.

\section{MODELAGEM HIDROGEOLÓGICA EM AMBIENTE SIG}

Uma das aplicações dos SIGs consiste em relacionar dados espaciais de diversas fontes a fim de descrever e analisar possíveis interações, fazer previsões com modelos e fornecer apoio aos gestores e tomadores de decisões.

De acordo com Bonham-Carter (1994), dentre os modelos em Sistema de Informações Geográficas, é importante a distinção dos três tipos baseados no tipo de relação que representam, como: o teórico, o híbrido e o empírico. Na classe teórica, o tipo de combinação é baseado em princípios físicos/químicos, utiliza equações de movimento, sendo aplicado na determinação de fluxo subterrâneo. A classe híbrida consiste nos modelos semiempíricos, utilizados principalmente na simulação de sedimentação e estabilidade de taludes. Já os modelos empíricos baseiam-se em combinações estatísticas ou heurísticas e têm como exemplo os modelos de previsão de potencial mineral.

Os métodos baseados em modelos empíricos subjetivos utilizam regras e valores de pesos estabelecidos subjetivamente, a partir do conhecimento do processo envolvido, e têm como objetivo estimar a importância relativa dos mapas de entrada. O Índice de Sobreposição consiste num desses modelos e a interação dos mapas (soma) é dada a partir de uma combinação de pesos. São utilizados mapas multiclasses, nos quais para cada classe é atribuída uma pontuação, possibilitando uma ponderação mais flexível. As tabelas de pontuação e os pesos dos mapas podem ser ajustados para refletir o julgamento do especialista no domínio da aplicação em causa (Bonham-Carter, 1994).

Dentre as modelagens realizadas em ambiente SIG para estudos hidrogeológicos, destaca-se a modelagem baseada no conhecimento empírico dos fatores que influenciam na ocorrência do fenômeno estudado, assim como a análise dos fatores com atribuição de pesos e cargas aos critérios utilizados a partir de regras ou métodos que auxiliem nessa decisão. Logo, as regras de decisão quanto ao relacionamento espacial entre os diferentes fatores e 
suas respectivas influências no fenômeno estudado constituem a essência da modelagem baseada no conhecimento (Gomes, 2008).

Nos seus trabalhos para a definição de áreas potenciais de ocorrência de água subterrânea utilizando Sensoriamento Remoto e Sistema de Informações Geográficas, Musa et al. (2000) propõem uma modificação do método DRASTIC (Aller et al., 1987), que consiste na substituição dos parâmetros presentes nesse modelo por outros determinantes para a ocorrência da água subterrânea. Os parâmetros utilizados foram: precipitação anual, uso e cobertura do solo, tipo de solo, elevação, declividade, densidade de drenagem, litologia e densidade de lineamentos. A esses parâmetros foram estabelecidos pesos e cargas para suas diferentes classes com o auxílio do Método Analítico Hierárquico. A avaliação geral e criação do modelo final de potencial de produtividade de águas subterrâneas permitiu a definição das áreas em 5 classes de potencial: muito baixo, baixo, moderado, alto e muito alto.

\section{MATERIAIS E MÉTODO}

A modelagem espacial de águas subterrâneas inclui fases de investigação que permitem uma aproximação adequada do ambiente real em sub-superfície, a partir da integração de fatores físicos naturais que contribuem no processo de infiltração da água precipitada . Essas fases consistem no levantamento de dados e informações, geração de novos dados, interpretação, integração e modelagem. A produção do modelo de potencial hídrico das águas subterrâneas contempla 5 fases representadas no fluxograma metodológico (Figura 3):

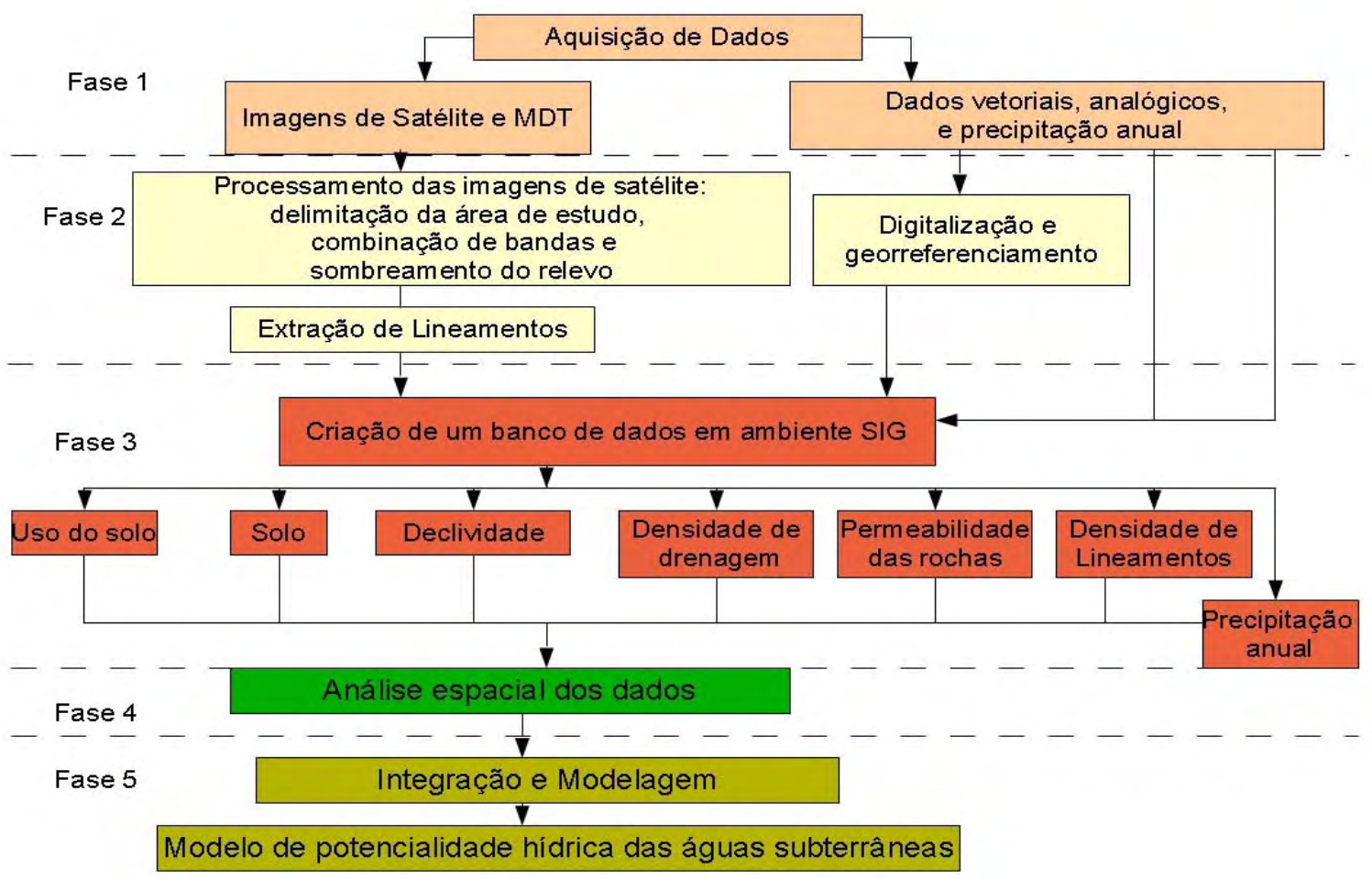

Figura 3. Fluxograma metodológico.

As bases de dados utilizadas no trabalho foram: o Atlas de Recursos Hídricos do Estado de Sergipe (Sergipe, 2004), Programa de Cadastro de InfraEstrutura Hídrica do NordesteEstado de Sergipe (CPRM, 2002) e o trabalho desenvolvido por Feitosa (1998) que apresenta dados dos poços de captação de água subterrânea na área de estudo. 
Para a identificação e extração de lineamentos estruturais foram utilizadas técnicas de processamento digital como a combinação de bandas em imagens de satélite e o sombreamento do relevo a partir do Modelo Digital do Terreno. Foram utilizadas imagens do satélite Landsat 5 TM (data do imageamento: 3 de abril de 2009) e Landsat 7 ETM+( data do imageamento: 7 de maio de 2001). Todas as imagens foram adquiridas gratuitamente no site do INPE.

O Modelo Digital do Terreno (produto gerado a partir de imagem do projeto SRTMShuttle Radar Topographic Mission da Nasa) da área de estudo foi obtido no site da Embrapa, por meio do projeto Brasil em Relevo (Miranda, 2005), que disponibiliza os dados préprocessados do projeto SRTM de todo território nacional, com resolução espacial de 90 metros.

A definição dos critérios adotados na análise do potencial hídrico das águas subterrâneas consiste na seleção de dados do meio físico natural representativos dos fenômenos ou evidências que permitem os processos de armazenamento e circulação da água no meio aquífero. O método utilizado no processo decisório de pesos aos critérios corresponde ao Método de Análise Hierárquica (Satty, 1990). Os critérios utilizados na modelagem são: precipitação, uso e cobertura do solo, tipo do solo, declividade, densidade de drenagem, densidade de lineamentos e geologia (permeabilidade das rochas).

No desenvolvimento do mapa de potencialidade hídrica das águas subterrâneas foram realizados procedimentos de processamento digital de imagens no software Envi 4.4® e de álgebra de mapas no ArcGis 9.3®. O Método de Análise Hierárquica foi utilizado na modelagem por meio da extensão AHP presente no ArcGis 9.3® e auxiliou na definição dos pesos aos diferentes critérios.

\subsection{Método de Análise Hierárquica}

Trata-se de um método de análise multicriterial denominado AHP (Analytical Hierarchy Process) ou Processo Analítico Hierárquico desenvolvido por Satty na década de 70 . Corresponde a uma metodologia flexível e eficaz de tomada de decisão que auxilia na definição de preferências e na escolha da alternativa, quando aspectos qualitativos e quantitativos devem ser ponderados.

A modelagem baseada no conhecimento implica atribuição de pesos aos critérios, muitas vezes de forma subjetiva. Para tornar mais criteriosa a aplicação de ponderadores aos fatores, utilizam-se métodos específicos, dentre eles o AHP. Esse método consiste na tomada de decisão com múltiplos critérios em que o problema apresenta uma hierarquia de solução a partir das variáveis que serão trabalhadas na resolução do problema. A hierarquização permite a criação de um modelo da realidade e visualização da interação dos componentes que separados em níveis garantem segurança e flexibilidade.

O método de análise hierárquica ou método analítico hierárquico é baseado na construção de uma série de matrizes (Tabela 1) de "pares de comparação" que comparam todos os critérios entre si. Isso é feito para estimar os pesos de cada critério, descrevendo o quanto este está contribuindo para atingir o objetivo geral do estudo.

Logo, os componentes das matrizes podem ser avaliados de acordo com seu grau de importância dentro da hierarquia estabelecida, sabendo-se que cada elemento revela quanto o critério da coluna esquerda é mais importante em relação a cada critério correspondente na linha superior, portanto, quando um critério é avaliado com si próprio, o único resultado possível é 1.

A consistência da matriz é calculada a partir da Razão de Consistência (CR), que mede quanto os valores de comparação entre os fatores foram gerados aleatoriamente. Se o CR for maior que 0,1 os julgamentos, ou seja, os valores de comparação atribuídos na construção da 
matriz, não são confiáveis. Logo, recomenda-se a reorganização da matriz, alterando os valores de comparação entre os fatores.

Tabela 1. Matriz de comparação dos critérios.

\begin{tabular}{c|ccccc}
\hline & \multicolumn{5}{c}{ CRITÉRIOS } \\
\cline { 2 - 6 } CRITÉRIOS & 1 & $\mathrm{G}_{12}$ & $\mathrm{G}_{13}$ & $\ldots \ldots$ & $\mathrm{G}_{1 \mathrm{j}}$ \\
& $1 / \mathrm{G}_{12}$ & 1 & $\mathrm{G}_{23}$ & $\ldots \ldots$ & $\mathrm{G}_{2 \mathrm{j}}$ \\
& $1 / \mathrm{G}_{13}$ & $1 / \mathrm{G}_{23}$ & 1 & $\ldots \ldots$ & $\mathrm{G}_{3 \mathrm{j}}$ \\
& $\ldots \ldots$ & $\ldots \ldots$ & $\ldots \ldots$ & 1 & $\ldots \ldots$ \\
& $1 / \mathrm{G}_{1 \mathrm{j}}$ & $1 / \mathrm{G}_{2 \mathrm{j}}$ & $1 / \mathrm{G}_{3 \mathrm{j}}$ & $\ldots \ldots$ & 1 \\
\hline
\end{tabular}

Fonte: Adaptado de Thirumalaivasan e Karmegam (2001).

As matrizes de comparação (Tabela 1) são traduzidas de uma linguagem verbal para a numérica pela Escala Fundamental de Satty, descrita na Tabela 2.

Tabela 2. Escala Fundamental adaptada de Satty (1990).

\begin{tabular}{|c|c|c|}
\hline Importância & Definição & Explicação \\
\hline 1 & Igual importância & $\begin{array}{l}\text { As duas atividades contribuem igualmente } \\
\text { para o objetivo }\end{array}$ \\
\hline 3 & Importância pequena & $\begin{array}{l}\text { O julgamento favorece levemente uma } \\
\text { atividade em relação à outra }\end{array}$ \\
\hline 5 & $\begin{array}{l}\text { Importância grande ou } \\
\text { essencial }\end{array}$ & $\begin{array}{l}\text { O julgamento favorece fortemente uma } \\
\text { atividade em relação à outra }\end{array}$ \\
\hline 7 & $\begin{array}{l}\text { Importância muito } \\
\text { grande }\end{array}$ & $\begin{array}{l}\text { Uma atividade é muito fortemente } \\
\text { favorecida em relação a outra }\end{array}$ \\
\hline 9 & Importância absoluta & $\begin{array}{l}\text { A evidência favorece uma atividade em } \\
\text { relação a outra }\end{array}$ \\
\hline $2,4,6,8$ & Valores Intermediários & $\begin{array}{c}\text { Quando há uma condição de compromisso } \\
\text { entre as duas definições }\end{array}$ \\
\hline
\end{tabular}

\subsection{Mapa de potencialidade hídrica das águas subterrâneas}

Para a elaboração do mapa de potencialidade hídrica das águas subterrâneas foi constituída uma base de dados cartográfica com os diferentes mapas representativos dos critérios de análise do potencial, são eles: geologia (permeabilidade das rochas), uso do solo, solo, declividade, precipitação, densidade de drenagem e densidade de lineamentos. A cada mapa foram atribuídas cargas para suas diferentes classes, e pesos de acordo com sua influência no objetivo principal do trabalho. A seguir são apresentadas as classes dos critérios aplicados na definição do mapa de potencial hídrico de águas subterrâneas (Tabela 3). 
RIBEIRO, D. D. de M.; ROCHA, W. de J. S. da F.; GARCIA, A. J. V. Modelagem da potencialidade hídrica das águas subterrâneas da sub-bacia do rio Siriri, Sergipe, Brasil, com base em Sistema de Informações Geográficas e técnicas de Sensoriamento Remoto. Ambi-Agua, Taubaté, v. 6, n. 2, p. 206-231, 2011. (doi:10.4136/ambi-agua.195)

Tabela 3. Cargas para as diferentes classes dos critérios utilizados na modelagem da potencialidade hídrica das águas subterrâneas.

\begin{tabular}{|c|c|}
\hline Precipitação anual (mm) & Cargas \\
\hline $1400-1700$ & 70 \\
\hline $1200-1400$ & 50 \\
\hline $1000-1200$ & 30 \\
\hline Uso e Cobertura do solo & Cargas \\
\hline Nuvens & 0 \\
\hline Área Degradada/Área Petrobras/Distrito/ & 10 \\
\hline Povoado/Sede Municipal/Extração Mineral & \\
\hline $\begin{array}{l}\text { Cultivos Agrícolas/Cana-de-Açúcar/Solos } \\
\text { expostos/ Lago/ Lagoa/ Açude/Pastagem }\end{array}$ & 20 \\
\hline Área Embrejada/Campos de Restinga/Capoeira & 30 \\
\hline Área Embrejada com vegetação & 40 \\
\hline Mata/Mata Ciliar & 50 \\
\hline Declividade (\%) & Cargas \\
\hline$(0-8)$ & 40 \\
\hline$(9-37)$ & 25 \\
\hline Densidade de Drenagem $\left(\mathrm{Km} / \mathrm{Km}^{2}\right)$ & Cargas \\
\hline $0-0,23645$ & 50 \\
\hline $0,23645-0,70936$ & 40 \\
\hline $0,70936-1,18226$ & 30 \\
\hline $1,18226-1,76718$ & 20 \\
\hline Geologia (Permeabilidade das rochas) & Cargas \\
\hline Sedimentos Costeiros e Aluvião & 45 \\
\hline Formação Barreiras (Aquífero Barreiras) & 30 \\
\hline $\begin{array}{l}\text { Formação Cotinguiba- Membro Sapucari } \\
\text { (Aquífero Sapucari) }\end{array}$ & 70 \\
\hline Formação Riachuelo- Membro Angico (Aquífero & 20 \\
\hline Angico) & \\
\hline Formação Riachuelo- Membro Maruim & 70 \\
\hline (Aquífero Maruim e Maruim/Aguilhada) & \\
\hline Formação Riachuelo- Membro Taquari & 20 \\
\hline Cornubianito Traipu & 15 \\
\hline Densidade de Fotolineamentos $\left(\mathrm{Km} / \mathrm{Km}^{2}\right)$ & Cargas \\
\hline $1,58661-2,92211$ & 50 \\
\hline $0,94740-1,58661$ & 30 \\
\hline $0,39950-0,94740$ & 20 \\
\hline $0-0,39950$ & 10 \\
\hline Tipos de solo & Cargas \\
\hline $\begin{array}{c}\text { Latossolo Vermelho-Amarelo Distrófico } \\
\text { (LVAd1) }\end{array}$ & 40 \\
\hline Argissolo Vermelho-Amarelo (PVA1) & 20 \\
\hline Argissolo Vermelho-Amarelo (PVA2) & 20 \\
\hline $\begin{array}{c}\text { Neossolos Flúvicos Eutróficos e Distróficos } \\
\text { (RYve/RYbd) }\end{array}$ & 20 \\
\hline Luvissolo Crômico Eutrófico (TC) & 10 \\
\hline Neossolo Quartzarenico hidromórfico (RQg) & 50 \\
\hline Vertissolo (V) & 10 \\
\hline Argissolo Vermelho-Amarelo (PVA7) & 20 \\
\hline Argissolo Vermelho-Amarelo (PVA9) & 20 \\
\hline
\end{tabular}

Os procedimentos cartográficos realizados no ArcGis 9.3® e no Envi 4.4® são descritos detalhadamente na modelagem cartográfica ( Figura 4). A extensão AHP permitiu a criação 
da matriz de comparação entre os critérios e a definição de pesos de acordo com a importância de cada critério na definição de áreas com potencial de ocorrência da água subterrânea. Os valores e pesos atribuídos na modelagem são amplamente discutidos com especialistas e têm como objetivo, definir quais dados de evidências são representativos e previsores do fenômeno estudado, ou seja, quais influenciam no armazenamento e circulação da água subterrânea. Em seguida, os valores da matriz comparativa e os pesos referentes a cada critério são atribuídos, e por meio da álgebra de mapas é gerado o mapa de potencial hídrico. A avaliação geral e criação do modelo consiste na classificação das áreas em 5 categorias de potencial: muito baixo, baixo, moderado, alto e muito alto. Também foi realizada a interpolação estatística Krigagem Ordinária para determinar a vazão média dos poços de captação de água subterrânea. Posteriormente, o mapa de potencialidade hídrica foi comparado ao mapa de vazão média para uma análise confirmativa dos resultados obtidos.

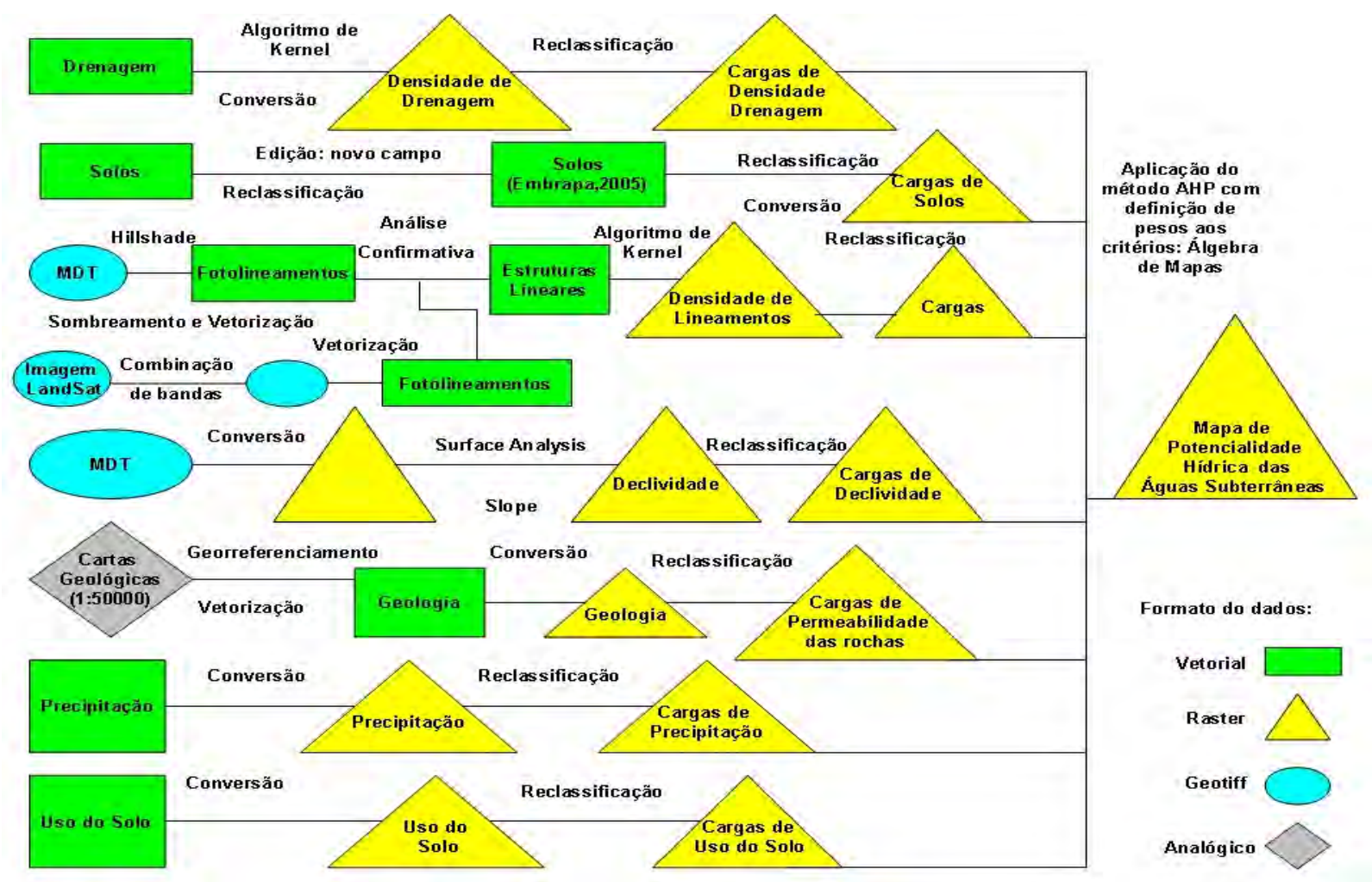

Figura 4. Modelagem cartográfica para elaboração do mapa de potencialidade hídrica das águas subterrâneas.

\section{RESULTADOS E DISCUSSÃO}

A modelagem da potencialidade hídrica das águas subterrâneas consistiu na análise e integração de mapas temáticos gerados a partir de dados geológicos, de poços produtores e de aspectos físicos-naturais determinantes na favorabilidade de ocorrência de água subterrânea. Cada mapa temático foi quantificado, de acordo com sua potencialidade para o armazenamento de água subterrânea. A modelagem final dos dados consiste na aplicação da análise multicriterial para a definição dos pesos de cada variável, segundo sua contribuição para a ocorrência de água subterrânea. 


\section{Geologia}

O conhecimento geológico de determinada área é o ponto inicial para o entendimento da distribuição dos aquíferos, reconhecidos como unidades geológicas capazes de armazenar e transmitir água.

No desenvolvimento desse critério foram estabelecidas classes de permeabilidade para as rochas das unidades geológicas presentes na sub-bacia do rio Siriri. Foram definidas 5 classes de permeabilidade entre muito baixa, baixa, moderada, alta e muito alta de acordo com observações no campo e bibliografias de caracterização de aquíferos (Tabela 4). O mapa geológico da Figura 5 apresenta as cargas geradas a partir da reclassificação realizada com base nas características de permeabilidade das diferentes unidades.

\section{Declividade}

A declividade é indispensável nos estudos hidrogeológicos uma vez que a inclinação do terreno é determinante na taxa de infiltração da água precipitada. Ou seja, quanto maior a declividade, maior o escoamento superficial, menor a infiltração. Apresentando assim, menor favorabilidade para a ocorrência da água subterrânea. O mapa de cargas para as diferentes classes de declividade é apresentado na Figura 6. Na área correspondente à carga 40 (classe de $0 \%$ a $8 \%$ ) o escoamento superficial é bastante reduzido, sendo excelente para a infiltração da água precipitada. Já na área da carga 25 (classe de 9\% a 37\%), o escoamento é moderado com infiltração regular da água.

\section{Tipo de Solos}

A permeabilidade e espessura do solo favorecem a infiltração da água precipitada. Assim, quanto maior a permeabilidade do solo, maior a favorabilidade para a ocorrência da água subterrânea. As cargas para os diferentes tipos de solo foram estabelecidas com fundamento na classificação hidrológica dos solos com base na sua capacidade de infiltração (Ward e Elliot, 1995). Assim, os solos da área de estudo foram classificados em: i) solos com alta capacidade de infiltração, formando solos profundos e com drenagem boa a excessiva ( na área de estudo correspondem ao latossolo e o neossolo quartzarênico); ii) solos com baixa capacidade de infiltração, formado por camadas impermeáveis que dificultam o movimento descendente da água ( na área de estudo corresponde ao argissolo vermelho-amarelo e o neossolo flúvico); iii) solos com capacidade de infiltração muito baixa, formados por solos argilosos com elevado potencial de agregação( na área de estudo foram estabelecidos nesta classe o luvissolo crômico e o vertissolo). O latossolo e o neossolo quartzarênico são os que apresentam melhor capacidade de infiltração por serem profundos e bem drenados (carga 40 e 50 respectivamente). O argissolo vermelho-amarelo e o neossolo flúvico apresentam baixa capacidade de infiltração, com textura areno-argilosa (carga 20). Já o luvissolo crômico e o vertissolo são ricos em argila e apresentam as condições menos favoráveis à infiltração (carga10). O mapa de cargas de solo é apresentado na Figura 7. 
RIBEIRO, D. D. de M.; ROCHA, W. de J. S. da F.; GARCIA, A. J. V. Modelagem da potencialidade hídrica das águas subterrâneas da sub-bacia do rio Siriri, Sergipe, Brasil, com base em Sistema de Informações Geográficas e técnicas de Sensoriamento Remoto. Ambi-Agua, Taubaté, v. 6, n. 2, p. 206-231, 2011. (doi:10.4136/ambi-agua.195)

Tabela 4. Atributos litológicos definidores de propriedades aquíferas (aplicados à área de estudo) e fatores adicionais passiveis de modificação de propriedades (modificado de Feitosa 1998; Brasil, 1975; Sergipe, 1992).

\begin{tabular}{|c|c|c|c|c|}
\hline \multicolumn{2}{|c|}{$\begin{array}{c}\text { Unidades } \\
\text { Geológicas/Aquíferos }\end{array}$} & Litotipos & $\begin{array}{l}\text { Fatores adicionais de influência } \\
\text { na permeabilidade }\end{array}$ & $\begin{array}{c}\text { Cargas } \\
\text { (Justificativas) }\end{array}$ \\
\hline \multicolumn{2}{|c|}{$\begin{array}{l}\text { Sedimentos } \\
\text { Costeiros e Aluvião }\end{array}$} & $\begin{array}{l}\text { Areias e cascalhos de origem aluvial ou fluvial ou } \\
\text { litorânea } \\
\text { Sedimentos síltico argilosos de origem fluvial ou } \\
\text { mangues costeiros }\end{array}$ & $\begin{array}{l}\text { Relacão de composicão arenosa (permeabilidade média a } \\
\text { alta) x síltico argilosa (permeabilidade baixa) }\end{array}$ & $\begin{array}{l}45 \\
\text { Pois ocorre a composição arenosa e } \\
\text { síltico argilosa com predominância da } \\
\text { primeira. }\end{array}$ \\
\hline \multicolumn{2}{|c|}{$\begin{array}{l}\text { Formação Barreiras } \\
\text { (Aquífero Barreiras) }\end{array}$} & $\begin{array}{l}\text { Sedimentos inconsolidados representados por } \\
\text { siltes, areias mal selecionadas e argilas. Clásticos } \\
\text { continentais finos a grosseiros, de coloração } \\
\text { variada e grau de compactação insignificante. } \\
\text { Arenito caolínico mal consolidado e cascalhos. } \\
\text { Na superfície ocasionais matacões }\end{array}$ & $\begin{array}{l}\text { Relacão de composicão arenosa (permeabilidade média a } \\
\text { alta) x síltico argilosa (permeabilidade baixa) }\end{array}$ & $\begin{array}{l}30 \\
\text { Pois há ocorrência de camadas } \\
\text { argilosas. }\end{array}$ \\
\hline $\begin{array}{l}\text { Formação } \\
\text { Cotinguiba }\end{array}$ & $\begin{array}{l}\text { Membro } \\
\text { Sapucari } \\
\text { (Aquífero } \\
\text { Sapucari) }\end{array}$ & $\begin{array}{l}\text { Essencialmente constituído por calcilutito } \\
\text { cinzento maciço ou estratificado. }\end{array}$ & $\begin{array}{l}\text { Granulometria em calcários granulares } \mathrm{x} \text { grau de } \\
\text { dissolucão em calcários em geral x grau de fraturamento } \\
\text { em calcários em geral }\end{array}$ & $\begin{array}{l}70 \\
\text { Pois mostra evidências de dissolução e } \\
\text { apresenta grau médio de fraturamento }\end{array}$ \\
\hline \multirow{3}{*}{$\begin{array}{l}\text { Formação } \\
\text { Riachuelo }\end{array}$} & $\begin{array}{l}\text { Membro } \\
\text { Angico } \\
\text { (Aquífero } \\
\text { Angico) } \\
\end{array}$ & $\begin{array}{l}\text { Arenito branco fino a conglomerático com } \\
\text { cimento calcifero. }\end{array}$ & Granulometria e grau de cimentacão & $\begin{array}{l}\mathbf{2 0} \\
\text { Pois apresenta granulometria } \\
\text { heterogênea (fina a conglomerática) e } \\
\text { apresenta cimento calcitico }\end{array}$ \\
\hline & $\begin{array}{l}\text { Membro } \\
\text { Maruim } \\
\text { (Aquífero } \\
\text { Maruim e } \\
\text { Maruim/Ag } \\
\text { uilhada) } \\
\end{array}$ & $\begin{array}{l}\text { Calcarenito e calcirrudito oncolítico e oolítico } \\
\text { creme, recifes algálicos isolados. Em 1994, Feijó } \\
\text { inclui no topo deste membro o calcário } \\
\text { dolomitizado, antes denominado de Membro } \\
\text { Aguilhada. }\end{array}$ & $\begin{array}{l}\text { Granulometria e grau de cimentacão } x \text { grau de } \\
\text { dissolucão x grau de fraturamento }\end{array}$ & $\begin{array}{l}\mathbf{7 0} \\
\text { Pois apresenta granulomria grossa a } \\
\text { média e dissolucão }\end{array}$ \\
\hline & $\begin{array}{l}\text { Membro } \\
\text { Taquari }\end{array}$ & Alternâncias de calcilutito e folhelhos cinzentos. & $\begin{array}{l}\text { Granulometria e grau de cimentacão x grau de dissolucão } \\
\text { x grau de fraturamento }\end{array}$ & $\begin{array}{l}\mathbf{2 0} \\
\text { Pois apresenta granulometria fina e alta } \\
\text { cimentação }\end{array}$ \\
\hline \multicolumn{2}{|c|}{ Cornubianito Traipu } & $\begin{array}{l}\text { Biotita, granada, cornubianito cinza-prateado } \\
\text { com porfiroblastos de biotita e ou granada. }\end{array}$ & $\begin{array}{l}\text { Rocha sem porosidade ou permeabilidade de origem } x \\
\text { fraturamento }\end{array}$ & $\begin{array}{l}15 \\
\text { Presença de fraturamento }\end{array}$ \\
\hline
\end{tabular}




\section{Uso do Solo}

A cobertura vegetal tem papel importante no processo de infiltração, uma vez que diminui o escoamento superficial das águas pluviais e aumenta o tempo de residência destas. Além disso, a vegetação exerce uma proteção à camada do solo, evitando a erosão hídrica ocasionada pelo escoamento superficial. Logo, quanto mais densa a cobertura vegetal, maior a infiltração. As áreas com mata ciliar e áreas embrejadas com vegetação possuem as melhores condições de infiltração na sub-bacia, recebendo cargas 50 e 40 respectivamente (Figura 8). Os campos de restinga, capoeira e área embrejada indicam situações intermediárias (carga 30). As áreas com pastagens e cultivos agrícolas receberam carga 20. Enquanto, as áreas degradadas, povoados, sedes municipais, e com atividades de extração mineral apresentam condições menos favoráveis a infiltração (carga 10).

\section{Densidade de Drenagem}

A densidade de drenagem reflete as características físicas da bacia, as rochas e os solos apresentam papel importante na resistência a erosão. A sub-bacia do rio Siriri insere-se num contexto geológico dominado por rochas da bacia sedimentar de Sergipe/Alagoas e de coberturas recentes com alta permeabilidade, como os arenitos. Áreas com ocorrências desse tipo de substrato geológico apresentam baixa densidade de drenagem. Assim, os baixos valores de densidade de drenagem (Figura 9) presentes na sub-bacia estão associados à presença de rochas permeáveis, relevo suave e solos arenosos que favorecem a infiltração da água precipitada.

\section{Precipitação}

A precipitação associada a outros fatores físicos da sub-bacia, como a geologia, o tipo do solo e a declividade apresentam importância fundamental na quantidade de água que será infiltrada. Na área de estudo, a precipitação média cresce à medida que se aproxima do exutório da bacia, o que permite um maior armazenamento de água nos aquíferos presentes nas áreas com maiores precipitações (Figura 10).

\section{Densidade de Lineamentos}

Os mapas de relevo sombreado mostraram-se mais adequados na identificação e análise dos lineamentos uma vez que estes apresentam ausência de feições superficiais, como a cobertura da vegetação e estradas, que influenciam na interpretação. A aplicação do sombreamento em diferentes direções de iluminação favorece o contraste dos lineamentos. Assim, foram elaborados diagramas de rosáceas com as frequências, agrupadas em classes de $10^{\circ}$, visando à determinação das orientações preferenciais.

Os dados obtidos foram integrados num mapa final (Figura 11), os lineamentos repetidos foram eliminados com o objetivo de evitar falsas análises. Assim, as direções de maiores destaques obtidas por meio das individualizações das lineações nos mapas de relevo sombreados somados as das imagens do satélite Landsat foram: N70-80E, N40-60E e N60$70 \mathrm{~W}$.

Observa-se nos mapas gerados que os padrões e intensidades de fraturamentos mostramse distintos nos setores da sub-bacia hidrográfica com substrato do embasamento ígneometamórfico (destacando-se as direções N0-10E, N70-80E, N60-70W e N80-90W) e da Bacia Sergipe-Alagoas ( destacando-se as direções N50-70E e N70-80E), sendo bem mais intensos no primeiro segmento, mesmo quando recobertos pelos depósitos da Formação Barreiras, o que favorece a infiltração e transmissão da água. As interseções dos lineamentos controlam a transmissão da água subterrânea por meio de orientações preferenciais. Quanto maior a densidade de lineamentos (Figura 12) maior é a probabilidade de ocorrência da água subterrânea. 
RIBEIRO, D. D. de M.; ROCHA, W. de J. S. da F.; GARCIA, A. J. V. Modelagem da potencialidade hídrica das águas subterrâneas da sub-bacia do rio Siriri, Sergipe, Brasil, com base em Sistema de Informações Geográficas e técnicas de Sensoriamento Remoto. Ambi-Agua, Taubaté, v. 6, n. 2, p. 206-231, 2011. (doi:10.4136/ambi-agua.195)

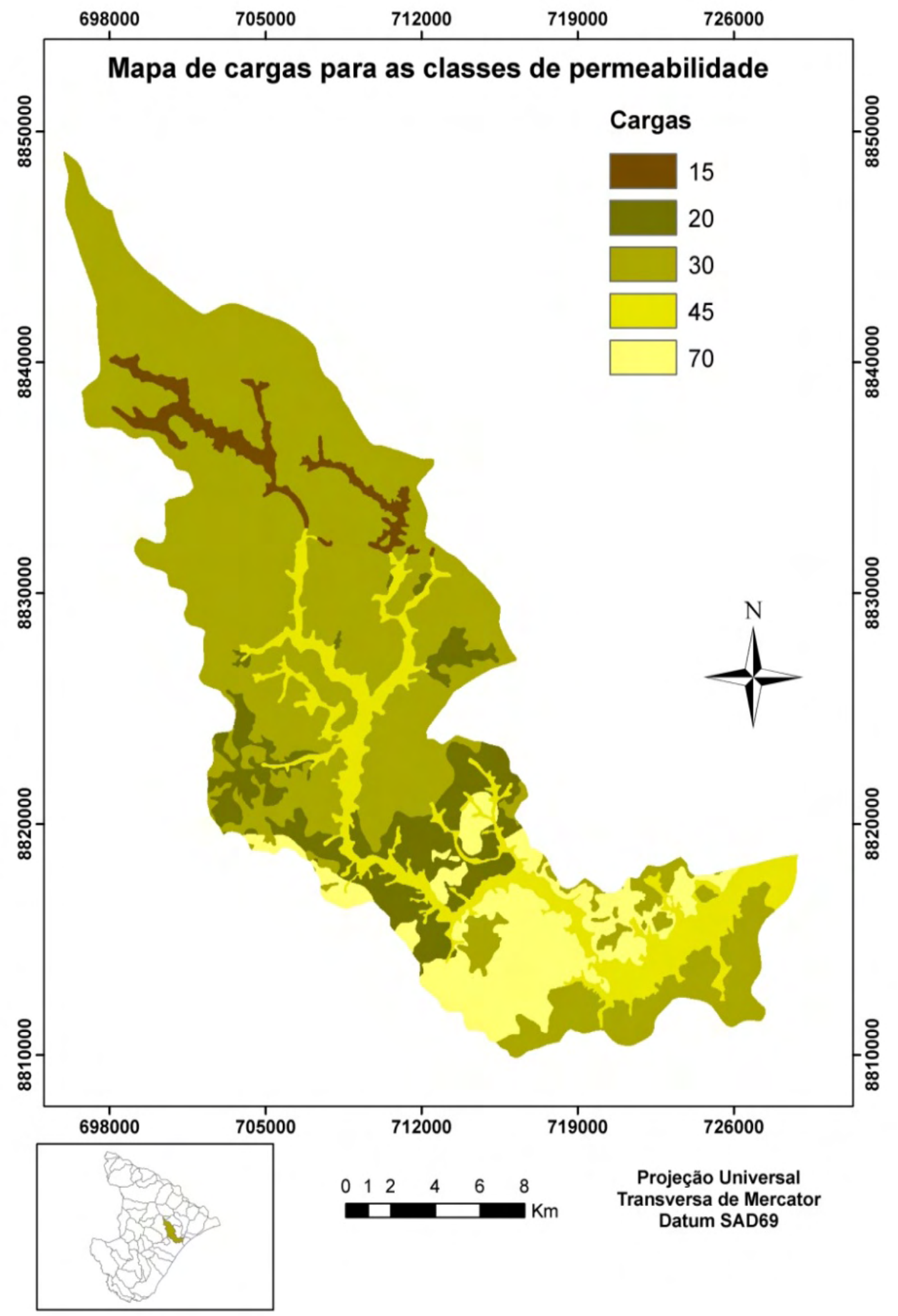

Figura 5. Mapa de cargas para as classes de permeabilidade 
RIBEIRO, D. D. de M.; ROCHA, W. de J. S. da F.; GARCIA, A. J. V. Modelagem da potencialidade hídrica das águas subterrâneas da sub-bacia do rio Siriri, Sergipe, Brasil, com base em Sistema de Informações Geográficas e técnicas de Sensoriamento Remoto. Ambi-Agua, Taubaté, v. 6, n. 2, p. 206-231, 2011. (doi:10.4136/ambi-agua.195)

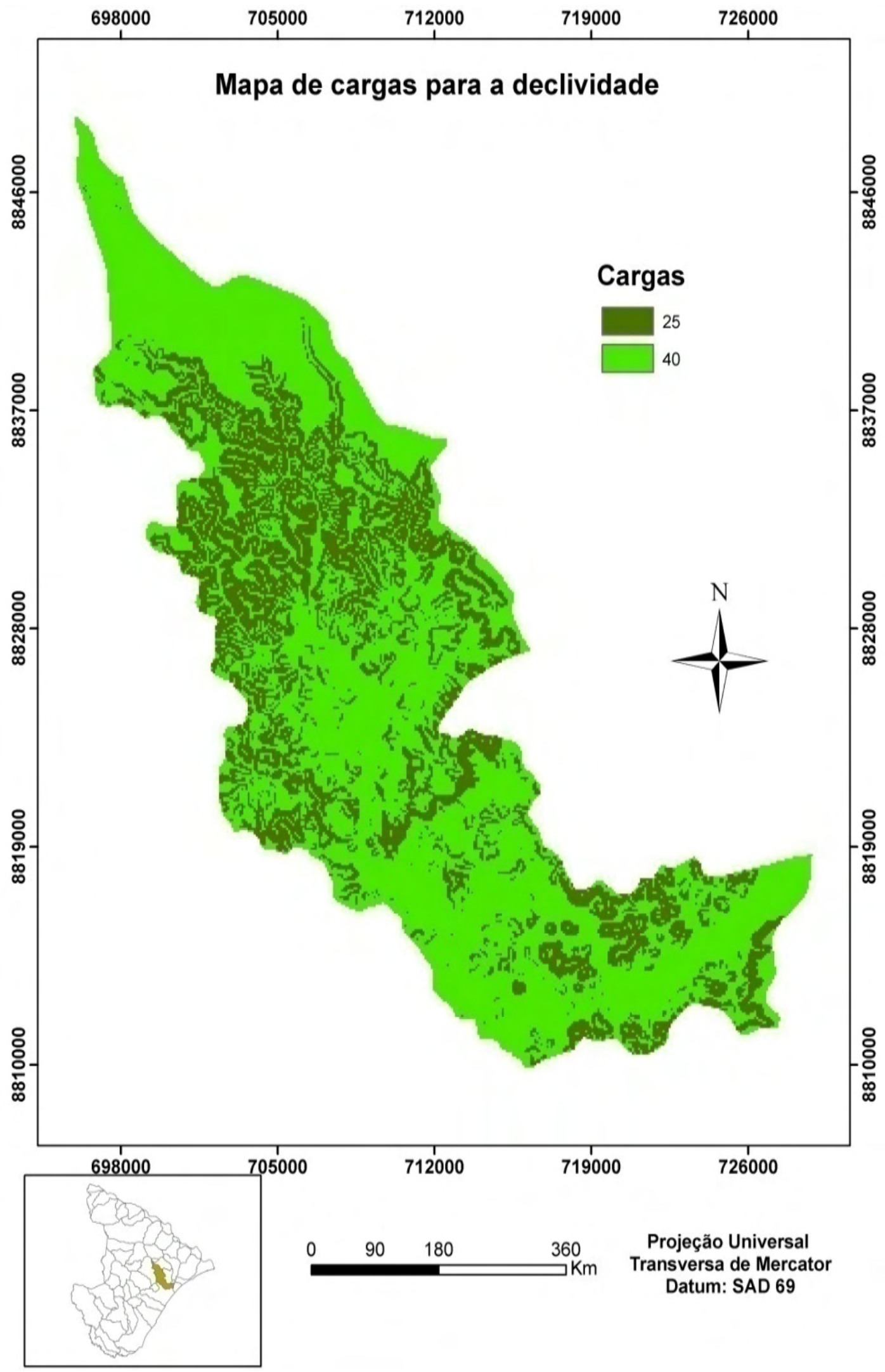

Figura 6. Mapa de cargas para declividade. 
RIBEIRO, D. D. de M.; ROCHA, W. de J. S. da F.; GARCIA, A. J. V. Modelagem da potencialidade hídrica das águas subterrâneas da sub-bacia do rio Siriri, Sergipe, Brasil, com base em Sistema de Informações Geográficas e técnicas de Sensoriamento Remoto. Ambi-Agua, Taubaté, v. 6, n. 2, p. 206-231, 2011. (doi:10.4136/ambi-agua.195)

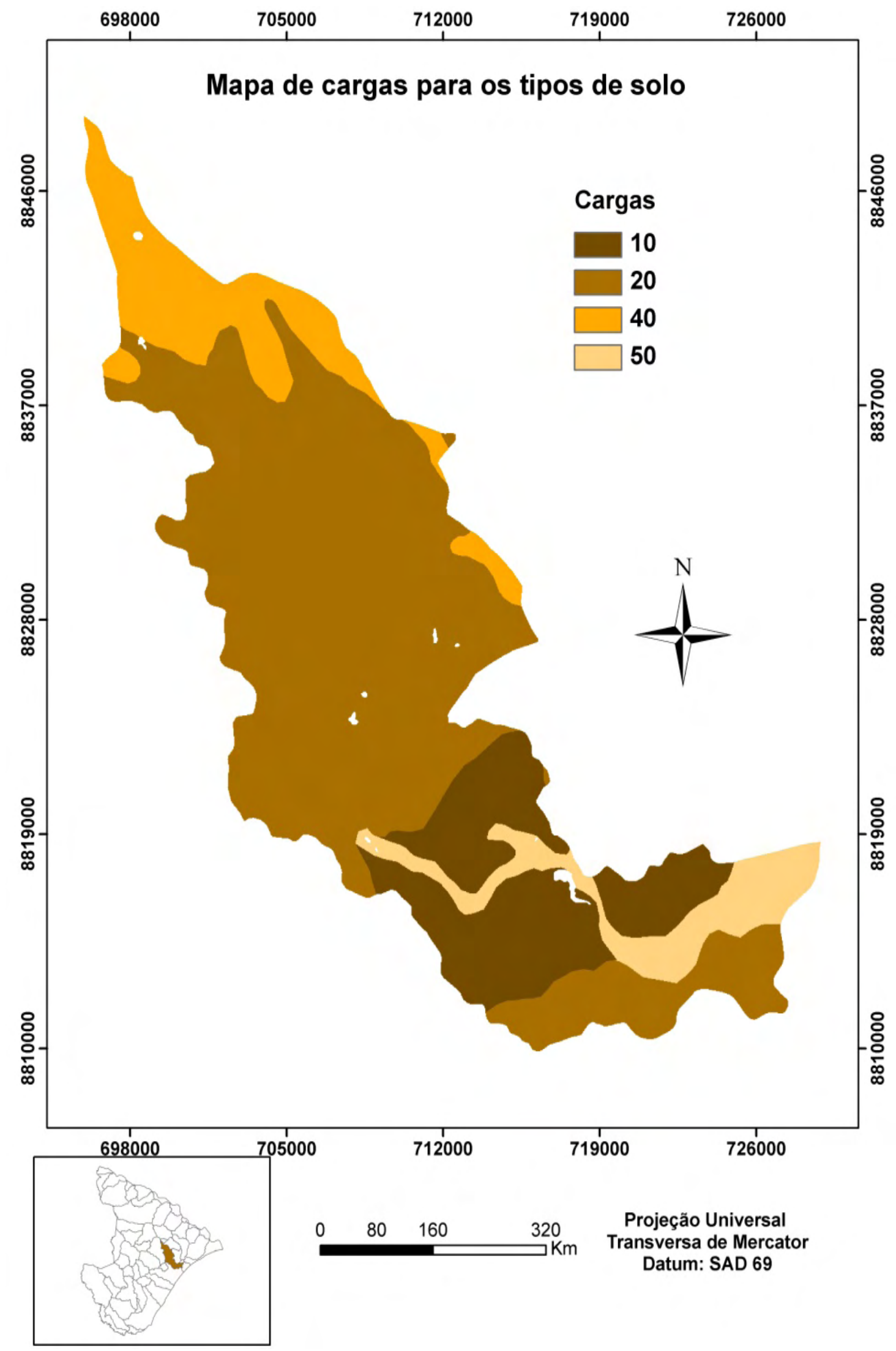

Figura 7. Mapa de cargas para os tipos de solo. 
RIBEIRO, D. D. de M.; ROCHA, W. de J. S. da F.; GARCIA, A. J. V. Modelagem da potencialidade hídrica das águas subterrâneas da sub-bacia do rio Siriri, Sergipe, Brasil, com base em Sistema de Informações Geográficas e técnicas de Sensoriamento Remoto. Ambi-Agua, Taubaté, v. 6, n. 2, p. 206-231, 2011. (doi:10.4136/ambi-agua.195)

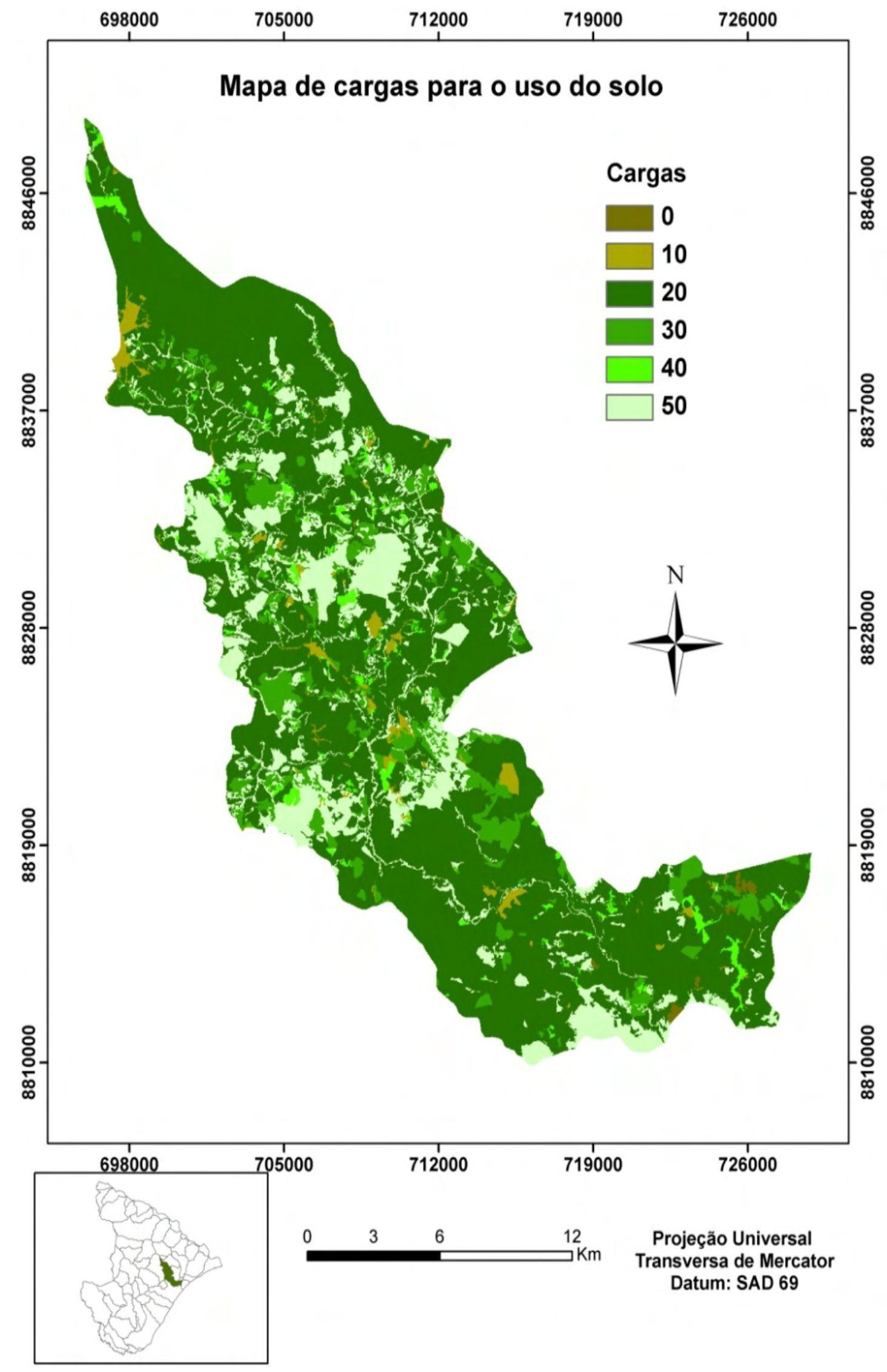

Figura 8. Mapa de cargas para os diferentes usos do solo. 
RIBEIRO, D. D. de M.; ROCHA, W. de J. S. da F.; GARCIA, A. J. V. Modelagem da potencialidade hídrica das águas subterrâneas da sub-bacia do rio Siriri, Sergipe, Brasil, com base em Sistema de Informações Geográficas e técnicas de Sensoriamento Remoto. Ambi-Agua, Taubaté, v. 6, n. 2, p. 206-231, 2011. (doi:10.4136/ambi-agua.195)

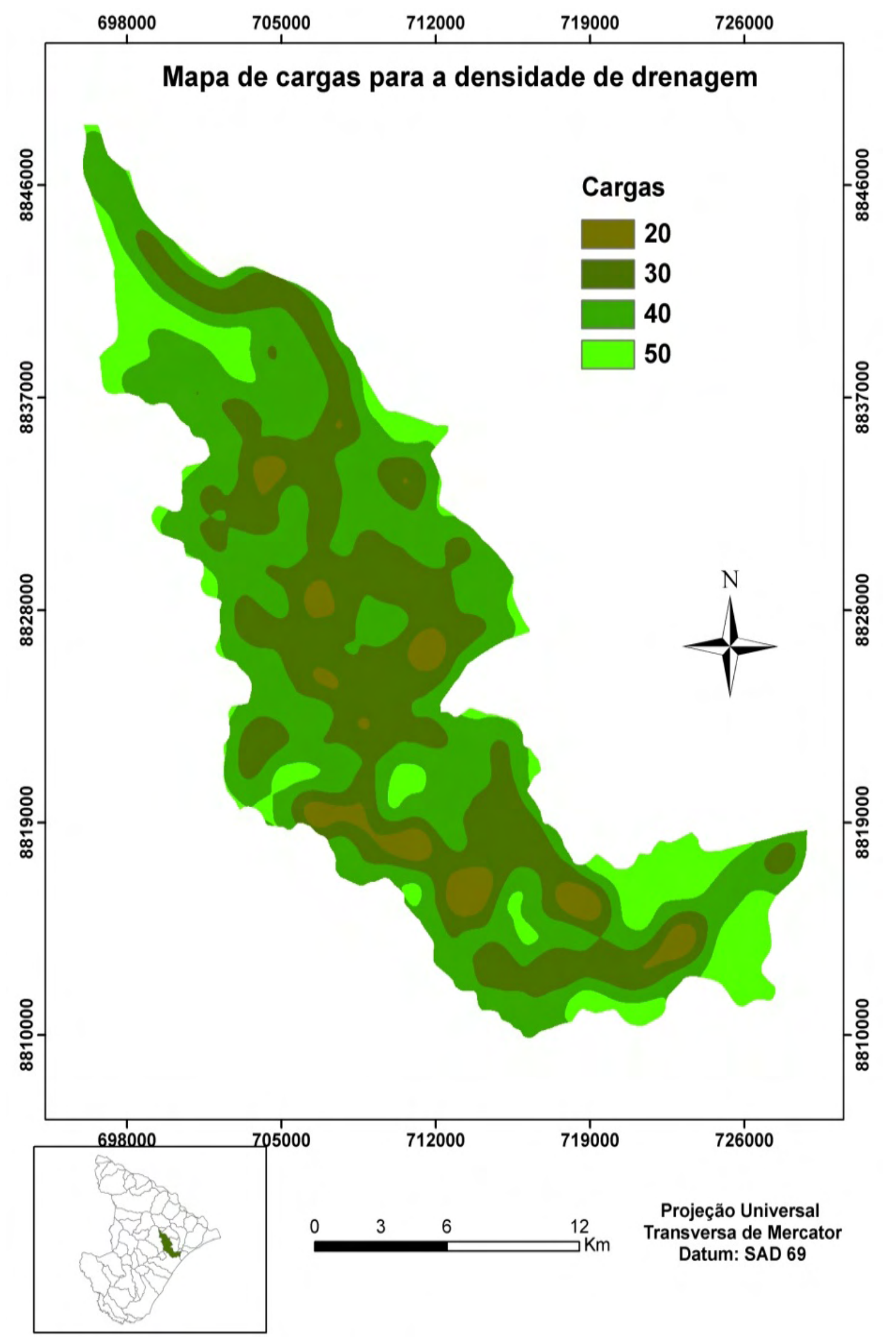

Figura 9. Mapa de cargas para a densidade de drenagem. 
RIBEIRO, D. D. de M.; ROCHA, W. de J. S. da F.; GARCIA, A. J. V. Modelagem da potencialidade hídrica das águas subterrâneas da sub-bacia do rio Siriri, Sergipe, Brasil, com base em Sistema de Informações Geográficas e técnicas de Sensoriamento Remoto. Ambi-Agua, Taubaté, v. 6, n. 2, p. 206-231, 2011. (doi:10.4136/ambi-agua.195)

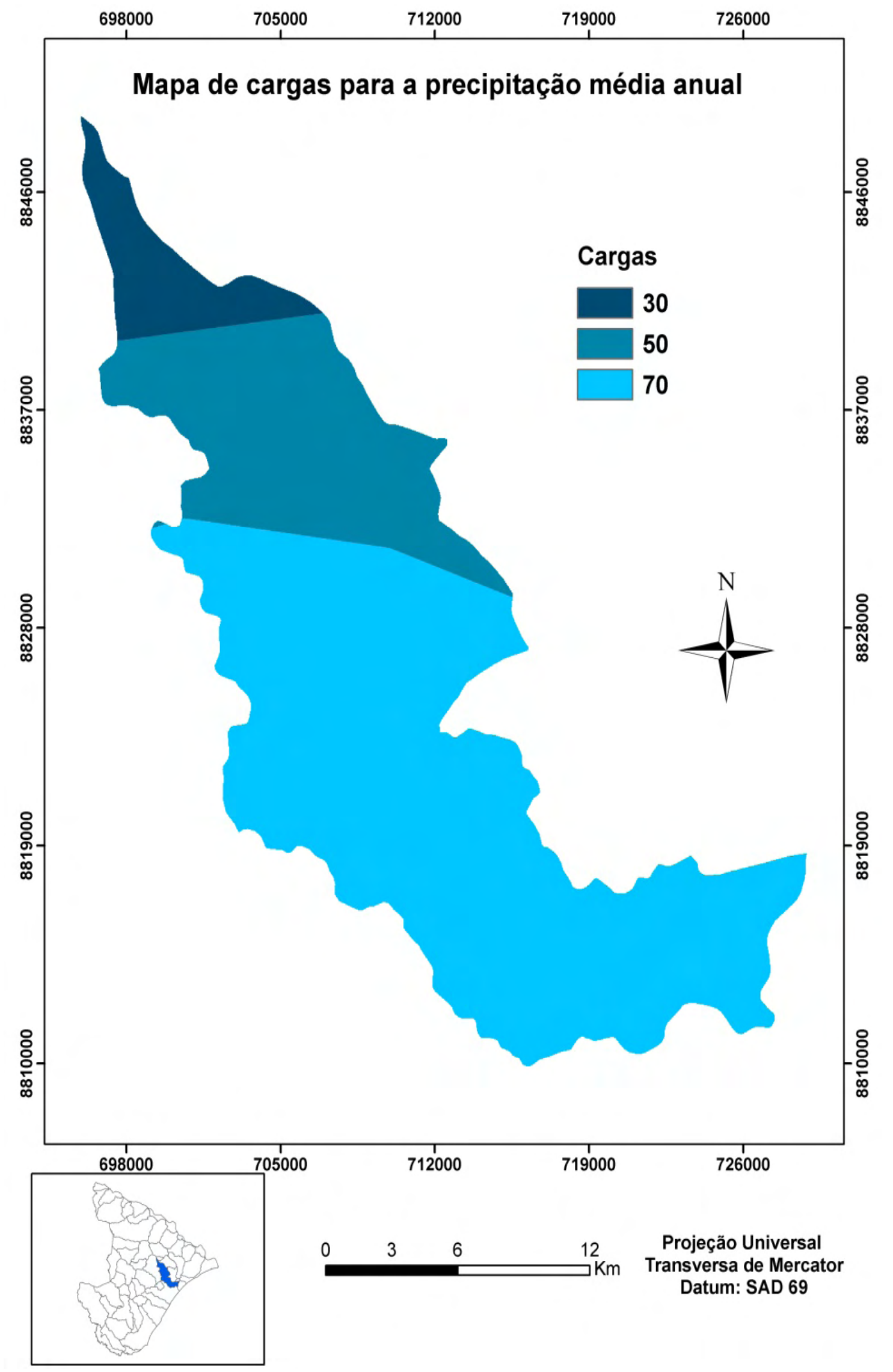

Figura 10. Mapa de cargas para a precipitação. 


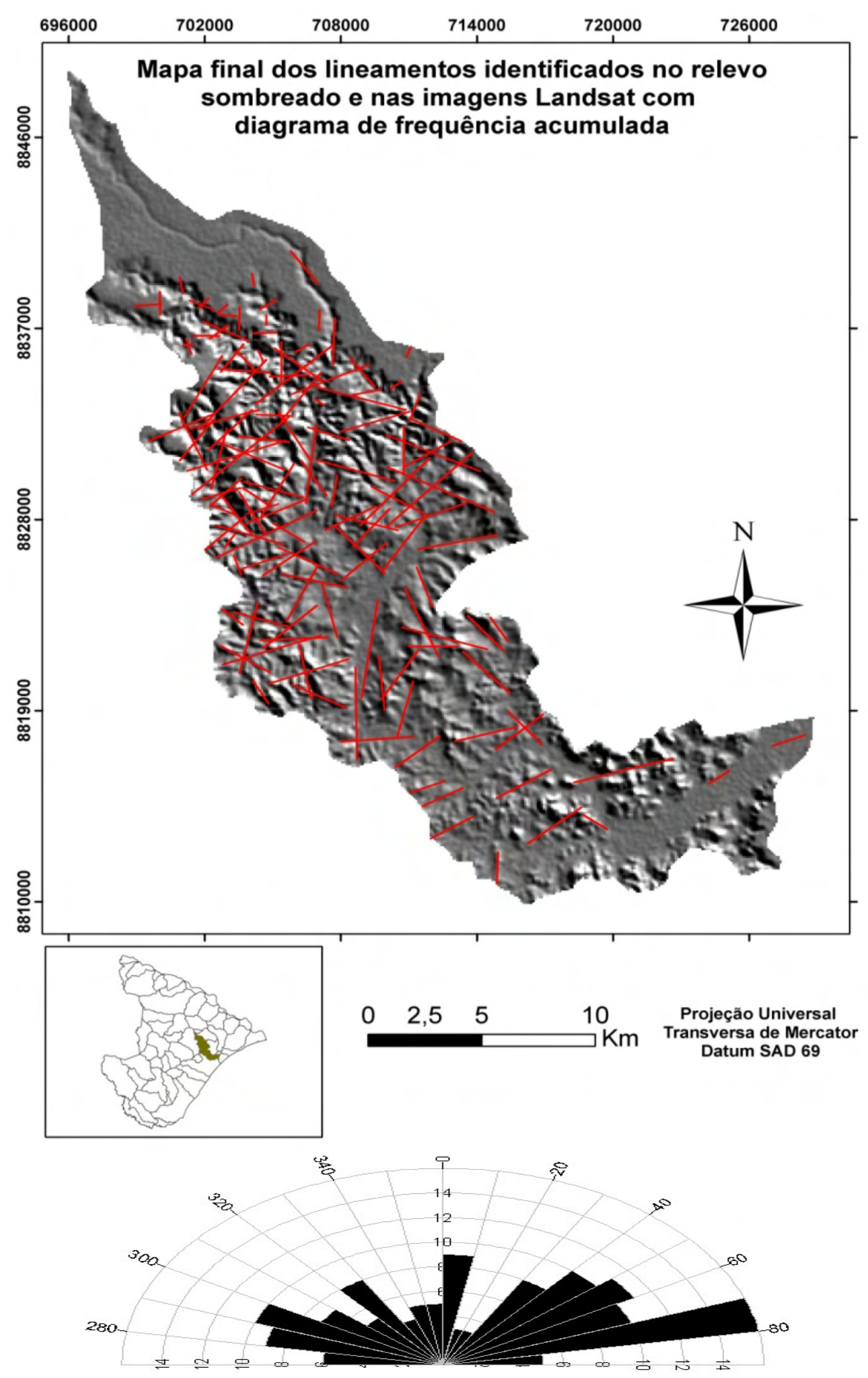

Figura 11. Mapa final dos lineamentos identificados no relevo sombreado e nas imagens Landsat com diagrama de frequência acumulada. 


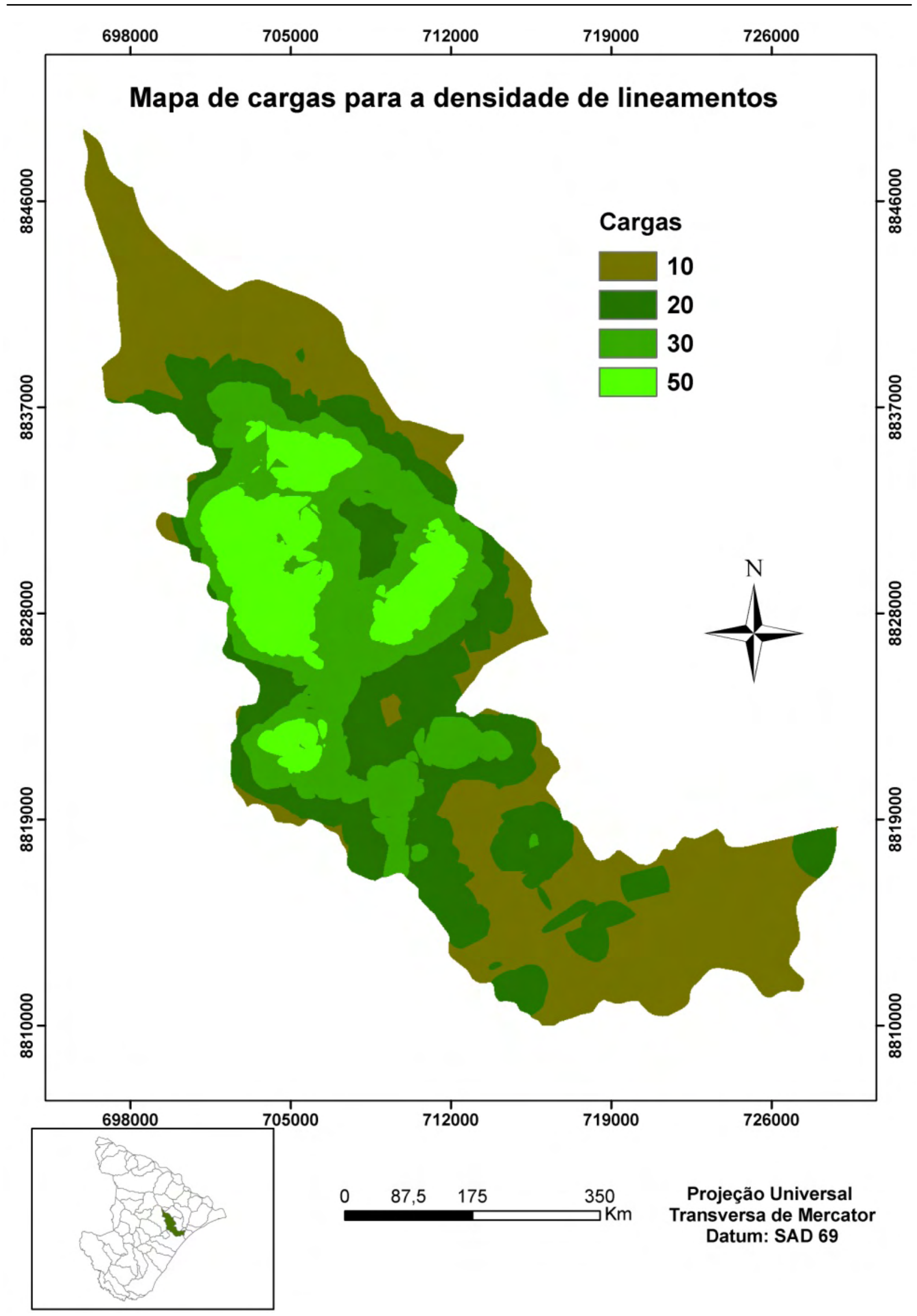

Figura 12. Mapa de cargas para a densidade de lineamentos.

A matriz de comparação (Tabela 5) entre os critérios foi elaborada com o objetivo de auxiliar na determinação dos pesos aos parâmetros utilizando-se como base a escala 
RIBEIRO, D. D. de M.; ROCHA, W. de J. S. da F.; GARCIA, A. J. V. Modelagem da potencialidade hídrica das águas subterrâneas da sub-bacia do rio Siriri, Sergipe, Brasil, com base em Sistema de Informações Geográficas e técnicas de Sensoriamento Remoto. Ambi-Agua, Taubaté, v. 6, n. 2, p. 206-231, 2011. (doi:10.4136/ambi-agua.195)

fundamental de Satty (1990). Os pesos definidos com o auxílio do AHP são apresentados na Tabela 6. A Razão de Consistência (CR) do AHP foi 0,03.

Tabela 5. Matriz de comparação entre os critérios.

\begin{tabular}{c|ccccccc}
\hline Critérios & Permeabilidade & $\begin{array}{c}\text { Densidade } \\
\text { de } \\
\text { Lineamentos }\end{array}$ & $\begin{array}{c}\text { Densidade } \\
\text { de } \\
\text { Drenagem }\end{array}$ & Solo & Precipitação & Declividade & $\begin{array}{c}\text { Uso } \\
\text { do } \\
\text { Solo }\end{array}$ \\
\hline $\begin{array}{c}\text { Permeabilidade } \\
\text { Densidade de }\end{array}$ & 1 & 4 & 3 & 5 & 6 & 9 & 9 \\
$\begin{array}{c}\text { Lineamentos } \\
\text { Densidade de } \\
\text { Drenagem }\end{array}$ & & 1 & 3 & 4 & 5 & 7 & 8 \\
$\quad$ Solo & & & 1 & 3 & 4 & 6 & 7 \\
Precipitação & & & & 1 & 5 & 5 & 7 \\
Declividade & & & & & 1 & 4 & 3 \\
Uso do solo & & & & & & & 1 \\
\hline
\end{tabular}

Tabela 6. Pesos dos parâmetros utilizados na elaboração do mapa de potencial hídrico das águas subterrâneas.

\begin{tabular}{l|c}
\multicolumn{1}{c|}{ Parâmetros } & Pesos (AHP) \\
\hline Permeabilidade & 0,3994 \\
Densidade de Lineamentos & 0,2384 \\
Densidade de Drenagem & 0,1554 \\
Solo & 0,1079 \\
Precipitação & 0,0511 \\
Declividade & 0,0268 \\
Uso do solo & 0,0211 \\
\hline
\end{tabular}

A integração desses mapas e a aplicação do método AHP em ambiente SIG permitiram a elaboração do mapa de potencialidade hídrica das águas subterrâneas. Os resultados dessa modelagem são apresentados no mapa da Figura 13.

Ao relacionar o mapa de potencialidade hídrica das águas subterrâneas da sub-bacia do rio Siriri com o mapa geológico e o mapa de vazões médias (Figura 14) dos poços presentes na área podem ser estabelecidas correspondências entre as categorias de potencial e as unidades mapeadas. Logo, verifica-se que as Coberturas Recentes formadas pelos sedimentos de praia e aluvião apresentaram potencial alto a muito alto, devido às características de permeabilidade média a alta dos sedimentos, que permitem a transmissão da água para reservatórios subterrâneos mais profundos. 
RIBEIRO, D. D. de M.; ROCHA, W. de J. S. da F.; GARCIA, A. J. V. Modelagem da potencialidade hídrica das águas subterrâneas da sub-bacia do rio Siriri, Sergipe, Brasil, com base em Sistema de Informações Geográficas e técnicas de Sensoriamento Remoto. Ambi-Agua, Taubaté, v. 6, n. 2, p. 206-231, 2011. (doi:10.4136/ambi-agua.195)

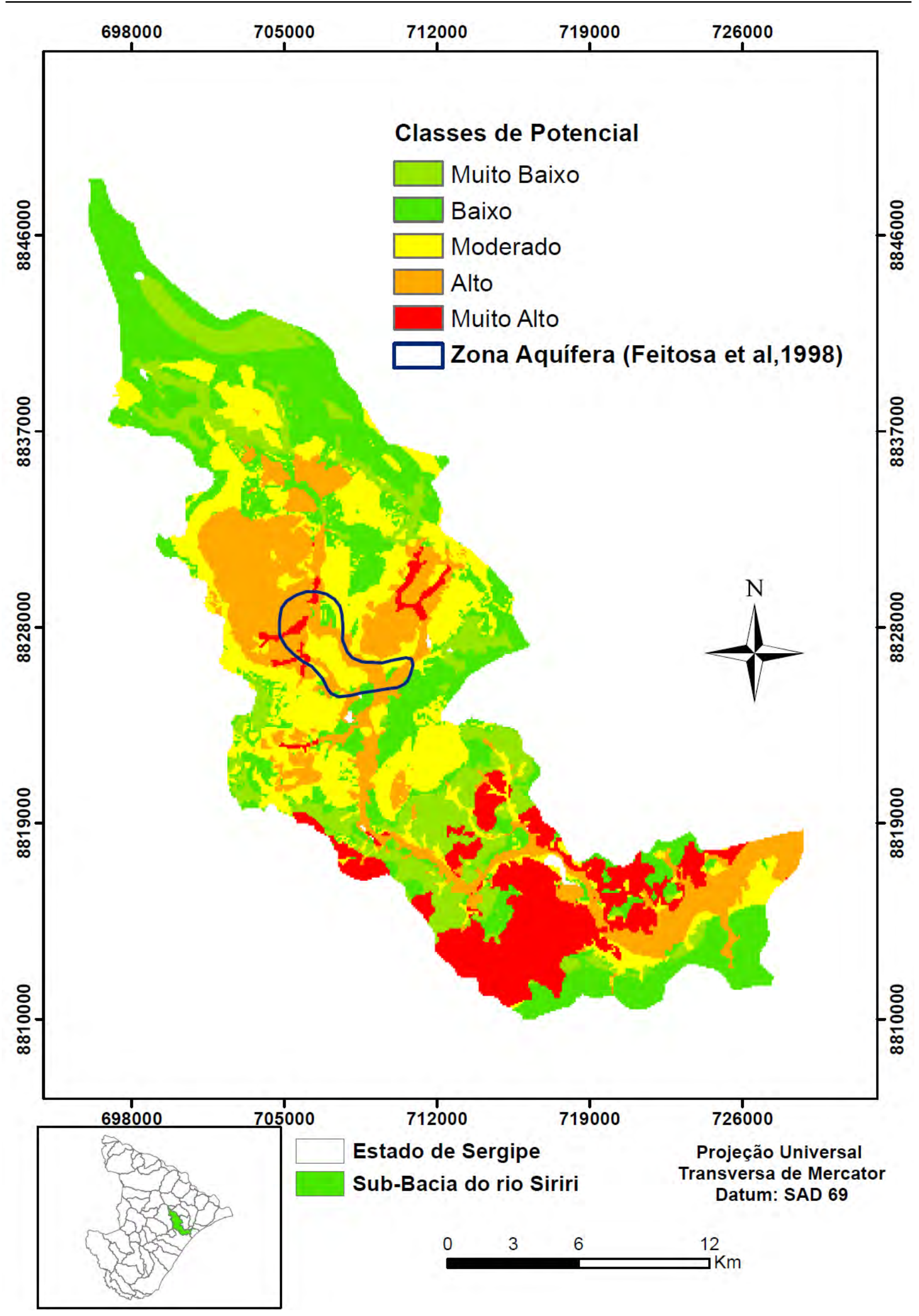

Figura 13. Mapa de potencialidade hídrica das águas subterrâneas da sub-bacia do rio Siriri. 
RIBEIRO, D. D. de M.; ROCHA, W. de J. S. da F.; GARCIA, A. J. V. Modelagem da potencialidade hídrica das águas subterrâneas da sub-bacia do rio Siriri, Sergipe, Brasil, com base em Sistema de Informações Geográficas e técnicas de Sensoriamento Remoto. Ambi-Agua, Taubaté, v. 6, n. 2, p. 206-231, 2011. (doi:10.4136/ambi-agua.195)

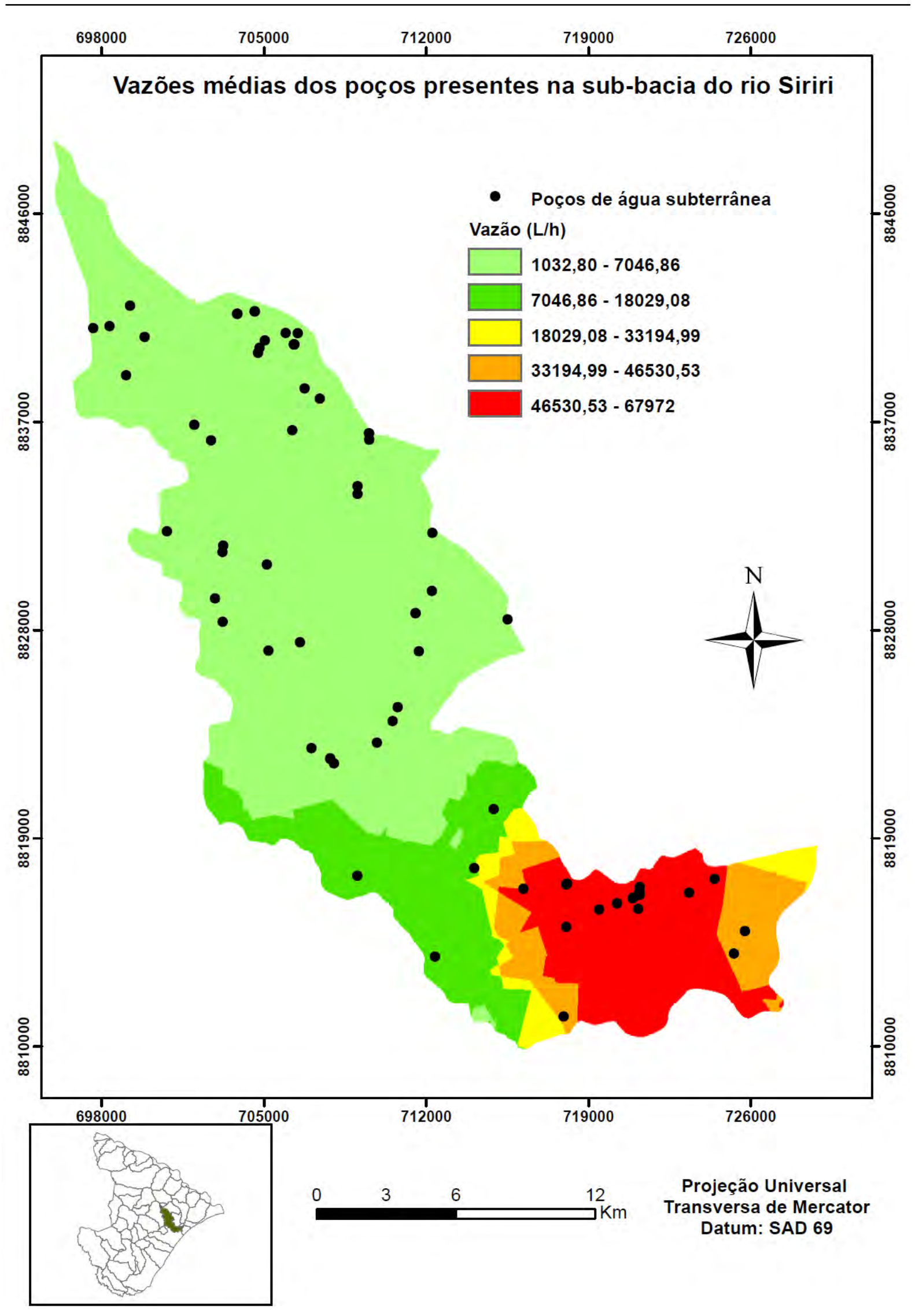

Figura 14. Mapa de vazões médias dos poços de captação de água subterrânea.

Já nas áreas correspondentes a Formação Barreiras observa-se um potencial hidrogeológico heterogêneo variando de baixo a alto, devido à presença de camadas 
impermeabilizantes de argila que dificultam a passagem da água. Também, nas áreas de alto potencial nota-se uma maior densidade de lineamentos estruturais que favorecem a infiltração e transmissão da água.

Os membros Maruim da Formação Riachuelo e o Sapucari da Formação Cotinguiba apresentaram potencial alto a muito alto devido à permeabilidade média a alta, as evidências de dissolução e fraturamento das rochas carbonáticas. O membro Angico da Formação Riachuelo apresentou potencial de baixo a médio devido à heterogeneidade dos arenitos (finos a conglomeráticos) com presença de cimento calcífero. O membro Taquari da Formação Riachuelo e o Cornubianito Traipu apresentaram potencial muito baixo devido às características de porosidade/permeabilidade praticamente nulas dessas unidades.

\section{CONCLUSÕES}

O Sistema de Informações Geográficas e o Sensoriamento Remoto têm sido constantemente utilizados na pesquisa hidrogeológica. A aplicação desses em estudo de bacias hidrográficas, particularmente na sub-bacia do rio Siriri, auxiliam no desenvolvimento de uma gestão de recursos hídricos subterrâneos sustentável, uma vez que permitem a interação do ambiente subterrâneo com o superficial.

A potencialidade hidrogeológica analisada a partir da modelagem em ambiente SIG dos fatores físicos e geológicos da sub-bacia do rio Siriri revelam a heterogeneidade potencial das diferentes unidades aquíferas, devido às características de permeabilidade das rochas e características físicas da bacia que permitem a infiltração da água precipitada para os reservatórios subterrâneos mais profundos.

As vazões médias dos poços calculadas confirmam o potencial dos aquíferos Maruim,Sapucari e Barreiras uma vez que são os mais explorados na sub-bacia hidrográfica,destacando-se o Sapucari com vazão média de $78113 \mathrm{~L} / \mathrm{h}\left(78,113 \mathrm{~m}^{3} / \mathrm{h}\right)$ e o Barreiras como maior número de poços de captação de água subterrânea e vazão média de $19332 \mathrm{~L} / \mathrm{h}\left(19,332 \mathrm{~m}^{3} / \mathrm{h}\right)$ respectivamente. Já o Aquífero Maruim possui uma vazão média de $12085 \mathrm{~L} / \mathrm{h}\left(12,085 \mathrm{~m}^{3} / \mathrm{h}\right)$.

\section{REFERÊNCIAS}

ALLER, L.; LEHR, J. H.; PETTY, R. DRASTIC: a standardized system of evaluating groundwater pollution potential using hidrogeologic settings. United States: EPA, 1987. Disponível em: <http://info.ngwa.org/GWOL/pdf/860138698.PDF>. Acesso em: 5 jun. 2009.

BONHAM-CARTER, G. F. Geographic information systems for geoscientists : modelling with GIS. New York: Pergamon, 1994. 398 p.

BRASIL. Departamento Nacional de Produção Mineral. Cartas geológicas da Bacia Sergipe/Alagoas. Maceió: PETROBRÁS, 1975.

BRASIL. Ministério do Meio Ambiente. Agência Nacional de Águas - ANA. Diagnóstico da oferta de água bruta e avaliação preliminar de alternativas técnicas no Estado de Sergipe: parte B. Brasília: MMA, 2005. 76p.

COMPANHIA DE PESQUISA DE RECURSOS MINERAIS - CPRM. Serviço Geológico do Brasil. Projeto cadastro de infra-estrutura hídrica do nordeste - Estado de Sergipe. Aracaju: CPRM, 2002. Disponível em: < http://www.cprm.gov.br/>. Acesso em: maio 2011. 
FEITOSA, E. C. (Coord.). Avaliação dos aquíferos da Bacia Sergipe/Alagoas entre Aracaju e Capela. Recife: LABHID; PETROBRAS, 1998. 175 p.

GOMES, F. E. M. Geoprocessamento em ambiente SIG aplicado à hidrogeologia. In: FEITOSA, F. C. (Org.). Hidrogeologia: conceitos e aplicações. Rio de Janeiro: CPRM; LABHID, 2008. 812 p.

MIRANDA, E. E. De (Coord.). Brasil em relevo. Campinas: Embrapa Monitoramento por Satélite, 2005. Disponível em: <http://www.relevobr.cnpm.embrapa.br>. Acesso em: 3 abril 2010.

MUSA, K. A.; JUHARI, M. A.; ABDULLAH, I. Groundwater prediction potential zone in Langat Basin using the integration of remote sensing and GIS. In: ASIAN CONFERENCE ON REMOTE SENSING, 21. 2000, Taipei. Proceedings... Disponível em: <http://www.remotesensing.gov.my/tmspublisher/images/default/bulletin02_khairulanam. pdf $>$. Acesso em: 20 março 2009.

SATTY, T. L. How to make a decision: the analitic hierarchy process. European Journal of Operational Research, North-Holland, v. 48, p. 9-26, 1990. http://dx.doi.org/10.1016/0377-2217(90)90057-I

SERGIPE. Secretaria de Estado do Desenvolvimento Urbano - SEDURB. Qualidade e disponibilidade de águas subterrâneas: folha Aracaju: SC.24.Z-B-IV. Aracaju: SEDURB, 1992. 1 Mapa.

SERGIPE. Secretaria de Planejamento e da Ciência e Tecnologia - SEPLANTEC. Superintendência de Recursos Hídricos de Sergipe - SRH. Atlas digital sobre recursos hídricos do Estado de Sergipe. Aracaju: SEPLANTEC, 2004. 1 CD-ROM.

THIRUMALAIVASAN, D.; KARMEGAM, M. Aquifer vulnerability assessment using analytic hierarchy process and GIS for Upper Palar Watershed. In: ASIAN CONFERENCE ON REMOTE SENSING, 22., 2001, Singapure. Proceedings... Disponível em: <http://www.crisp.nus.edu.sg/ acrs2001/pdf/267THIRU.PDF>. Acesso em: 22 março 2009.

WARD, A. D.; ELLIOT, W. J. Environmental hydrology. Boca Raton: Lewis Publishers, 1995. 462p. 